\title{
AVALIAÇÃO DA QUALIDADE DE SEMENTES DE Tabebuia serratifolia VAHL NICH. E $T$. impetiginosa(MARTIUS EX A. P. DE CANDOLLE) STANDLEY - (BIGNONIACEAE) PELO TESTE DE RAIOS $X^{1}$
}

\author{
LUCIANAMAGDADE OLIVEIRA ${ }^{2}$, MARIALAENE MOREIRADE CARVALHO ${ }^{3}$, RENATO MENDES \\ GUIMARÃES ${ }^{3}$, TATHIANAELISAMASETTO ${ }^{4}$
}

\begin{abstract}
RESUMO - Para estudar a eficiência do teste de raios X na avaliação de defeitos internos em sementes de ipê-amarelo (Tabebuia serratifolia) e ipê-roxo (T. impetiginosa), bem como verificar a conseqüência destes defeitos na germinação, as sementes foram submetidas a diferentes intensidades e tempos de exposição à radiação. Definida a intensidade de $55 \mathrm{kV}$ por 25 segundos como sendo a que permitiu melhor visualização das estruturas internas, as sementes das duas espécies foram divididas em três categorias de acordo com a sua análise radiográfica em: Sem Defeitos, Com Defeitos e Vazias. As Sementes Com Defeitos foram divididas em três subcategorias: Com Pequenos Danos (menos de 50\% do embrião danificado), Com Danos Severos (mais de 50\% do embrião danificado) e Deformadas. As sementes foram, então, submetidas ao teste de germinação em substrato sobre areia, a $30^{\circ} \mathrm{C}$, sob luz constante. O teste de raios X é eficiente na avaliação de defeitos em sementes de ipê-amarelo e ipê-roxo. Defeitos internos detectados nas radiografias afetam a germinação dessas sementes, reduzindo a qualidade do lote.
\end{abstract}

Termos para indexação: ipê-amarelo, ipê-roxo, germinação

EVALUATION OF SEED QUALITY IN Tabebeuia serratifolia VAHL NICH. AND $T$. impetiginosa (MARTIUS EXA. P. DE CANDOLLE) STANDLEY - (BIGNONIACEAE) BY XRAYTEST.

\begin{abstract}
To study the efficiency of the X-ray test on the evaluation of internal damage in yellow ipê (Tabebuia serratifolia) and purple ipê (T. impetiginosa) seeds and to verify the effect of damage on germination, the seeds were submitted to different times and intensity of radiation exposition. The intensity of $55 \mathrm{kV}$ for 25 seconds allowed the best visualization of the internal structures. After that, the seeds of both species were divided into three categories according to their internal anatomy visualized by the radiographs: whole seeds, seeds with damage and empty seeds. The seeds with damage were divided into three sub-categories: seeds with little damage, seeds with severe damage and deformed seeds. The seeds were submitted to the germination test in sand at $30^{\circ} \mathrm{C}$ under constant light. The X-ray test was efficient in the evaluation of internal damage in yellow ipê and purple ipê seeds. The internal damage observed by radiographs affected germination of ipê seeds decreasing seed lot quality.
\end{abstract}

Index Terms: yellow ipe, purple ipe, germination

${ }^{1}$ Submetido em 22/04/2004. Aceito para publicação em 24/08/2004. Parte da Tese de Doutorado do primeiro autor apresentada à Universidade Federal de Lavras (UFLA).

${ }^{2}$ Eng. Florestal, Dra - UFLA, Caixa Postal 37, CEP37200-000. Lavras, MG.lumagda@ufla.br
${ }^{3}$ Eng. Agrônomos, Drs Profs. - UFLA, 37200-000. Lavras, MG. mlaenemc@ufla.br

${ }^{4}$ Eng. Agrônoma, Mestranda - UFLA, 372000-000. Lavras, MG. tmasetto@ig.com.br 


\section{INTRODUÇ̃̃O}

O teste de raios $\mathrm{X}$ é um método rápido e não destrutivo, que é recomendado pela ISTA (1999) para a análise das estruturas internas das sementes, possibilitando a detecção de sementes cheias, defeituosas e vazias. A informação sobre a ocorrência de sementes defeituosas e vazias é altamente desejável, já que essas sementes influenciam os resultados de germinação de um lote (Craviotto et al., 2002).

Da mesma forma, o teste de raios $\mathrm{X}$ torna-se útil quando realizado durante os vários processos em que as sementes são submetidas, como por exemplo, durante o beneficiamento quando as sementes podem ser prejudicadas mecanicamente e tais danos podem ser invisíveis ao olho humano. A presença de sementes infestadas por insetos também é fácil e rapidamente detectada na radiografia, o que pode evitar a transferência destas sementes de uma região para outra.

Quando a semente é exposta aos raios X, a radiação é absorvida em vários graus, dependendo da espessura, densidade e composição da semente e do comprimento de onda da radiação, criando assim uma imagem permanente no filme radiográfico (Bino et al., 1993). As áreas mais escuras da radiografia correspondem àquelas partes que são facilmente penetradas pelos raios X; enquanto que áreas mais claras da radiografia representam partes mais densas da semente (Simak, 1991).

As pesquisas envolvendo este método têm avançado significativamente em espécies florestais. Oliveira et al. (2003) concluíram que o uso da técnica de raios $\mathrm{X}$ permite avaliar danos internos que afetam a germinação de sementes de Peltophorum dubium (canafistula). Machado \& Cícero (2003) salientaram que a técnica de raios $\mathrm{X}$ é eficiente na detecção de danos e anormalidades em embriões de Lithraea molleoides (aroeira-branca) e que o descarte dessas sementes pode melhorar a germinação do lote.

$\mathrm{O}$ uso do teste de raios $\mathrm{X}$ em sementes do gênero Tabebuia pode trazer grandes contribuições tecnológicas, já que aspectos morfológicos dessas sementes impedem a visualização de embriões defeituosos ou mesmo de sementes vazias, comuns nesse gênero; entretanto, a eficiência do teste depende de metodologia específica para cada espécie, o que ainda não foi estabelecido para sementes de Tabebuia serratifolia (ipê-amarelo) e T. impetiginosa (ipê-roxo).

O objetivo deste trabalho foi estudar a eficiência do teste de raios X na avaliação dos defeitos internos em sementes de ipê-amarelo e ipê-roxo, bem como verificar a conseqüência destes defeitos na germinação.

\section{MATERIAL E MÉTODOS}

O trabalho foi desenvolvido no Laboratório de Propagação de Plantas do Departamento de Ciências Florestais e Laboratório de Análise de Sementes do Departamento de Agricultura, na Universidade Federal de Lavras (UFLA). Os frutos foram colhidos em diversas matrizes no município de Lavras, MG, nos anos de 1998 e 2002, para o ipê-amarelo e 2000 e 2002, para o ipê-roxo. Por ocasião da colheita, as sementes de ambas as espécies estavam com umidade em torno de $40 \%$. As sementes foram beneficiadas manualmente, secas em galpão por cinco dias e armazenadas em sacos de polietileno em câmara com controle de temperatura e umidade $\left(6^{\circ} \mathrm{C}-9^{\circ} \mathrm{C} ; 70 \% \mathrm{UR}\right)$. O lote colhido em 1998 foi armazenado por quatro anos, o lote colhido em 2000 por dois anos e os lotes colhidos em 2002 por três meses. As sementes de todos os lotes foram mantidas, por 24 horas, em condições ambientais antes da realização dos experimentos.

As sementes tiveram sua umidade determinada pelo método de estufa a $103 \pm 2^{\circ} \mathrm{C}$ por 17 horas (Brasil, 1992), com quatro repetições de um grama de sementes por lote.

Para a definição de tempos e intensidades de radiação que permitissem a visualização mais nítida das estruturas e/ ou defeitos internos em sementes de ipê foram testadas intensidades de radiação que variaram de 30 a $60 \mathrm{kV}$ e tempos de exposição de 20 a 50 segundos.

As sementes foram acondicionadas em placas de acrílico e expostas à radiação no equipamento Faxitron HP, modelo 43855AX, com utilização do filme radiográfico Kodak Min-R 2000, tamanho $18 \times 24 \mathrm{~cm}$. A revelação foi realizada em uma processadora de revelação de raios $\mathrm{X}$ marca Kodak, modelo M35X OMAT.

Definidos a intensidade e o tempo de radiação de $55 \mathrm{kV}$ por 25 segundos, 400 sementes de cada lote foram radiografadas e, de acordo com a anatomia interna, visualizada nas radiografias, divididas em três categorias: Sem Defeitos, Com Defeitos e Vazias. As sementes Com Defeitos foram, então, divididas em três subcategorias: Com Pequenos Danos (menos de 50\% do embrião danificado), Com Danos Severos (mais de 50\% do embrião danificado) e Deformadas (Figura $1)$.

Para verificar a influência de defeitos internos sobre a germinação, sementes de todas as categorias, exceto sementes Vazias, e subcategorias foram numeradas e submetidas ao teste de germinação. As sementes foram desinfestadas com solução de hipoclorito de sódio $2 \%$ por 2 minutos e submetidas ao teste de germinação em substrato sobre areia, a $30^{\circ} \mathrm{C}$ sob 

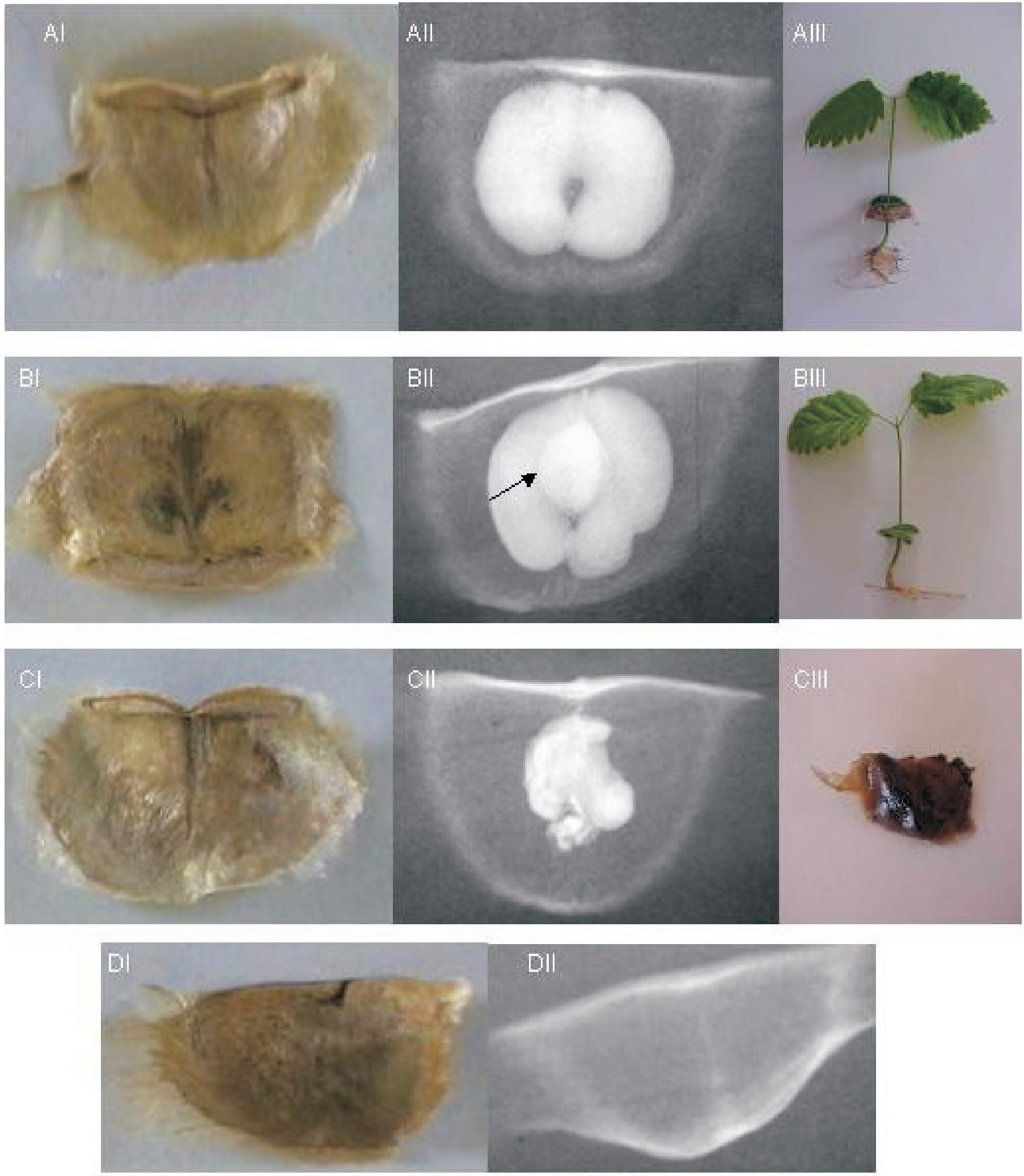

FIGURA 1. Sementes de Tabebuia spp visualmente intactas (AI, BI, CI e DI), classificadas pela análise radiográfica de acordo com a anatomia interna em: AII -Semente Sem Defeito, BII -Semente Com Pequenos Danos, CII -Semente Deformada e DII -Semente Vazia; originando plântulas normais (AIII e BIII) e semente morta (CIII). UFLA, Lavras, MG, 2004. 
luz constante. As avaliações foram feitas de acordo com as Regras para Análise de Sementes (Brasil, 1992), aos 28 dias após a semeadura (Machado, 1999).

Os dados obtidos no teste de germinação foram transformados utilizando arc sen. raiz quadrada $\mathrm{x} / 100 \mathrm{e}$ submetidos à análise de variância. As médias dos tratamentos foram comparadas pelo teste de Tukey, usando o programa SANEST (Zonta et al., 1985).

\section{RESULTADOS E DISCUSSÃO}

As sementes lotes de ipê-amarelo estavam com 9,3\% de umidade para o lote 1998 e $7 \%$ para o lote 2002 , e as de ipê-roxo, $8 \%$ e $8,3 \%$ de umidade para os lotes 2000 e 2002, respectivamente, por ocasião da realização dos testes. Essa baixa umidade favorece a visualização das estruturas das sementes durante a análise radiográfica. Segundo Simak (1991), a umidade das sementes influencia a densidade ótica, ou seja, quanto menor a umidade das sementes, maior a densidade ótica, o que possibilita uma maior diferenciação das estruturas das sementes visualizadas nas radiografias.

Os tempos e as intensidades testadas possibilitaram a visualização das estruturas internas das sementes de ipêamarelo e ipê-roxo, porém, o tempo de 25 segundos e a intensidade de $55 \mathrm{kV}$ permitiram uma visualização mais nítida, o que facilitou a categorização dos defeitos. Em estudos relacionados a sementes de espécies florestais, têm sido utilizados tempos que variam de 10 segundos a 4 minutos com intensidades de 10 a 50 kVs (Battisti et al., 2000; Mattos \& Medeiros, 2000; Oliveira et al., 2003). A variação encontrada entre as diferentes espécies em relação à intensidade e tempo de exposição das sementes à radiação é devido às diferenças na espessura, densidade, composição e aparelho utilizado (ISTA, 1999).

Os lotes utilizados, de ambas as espécies, apresentavam uma maior porcentagem de sementes da categoria Sem Defeitos (Tabela 1). Sementes dessa categoria, pertencentes a lotes armazenados há menos tempo, originaram, em sua maioria, maior porcentagem de plântulas normais; enquanto que, nos lotes armazenados há mais tempo, a maior parte das sementes dessa categoria resultou em sementes mortas (Tabela 2). Esse resultado pode ser devido à presença de sementes mortas, originadas durante o processo natural de envelhecimento, ou em estádios mais avançados de deterioração (Burg et al., 1994). Esse comportamento foi observado também em sementes de canafístula, como citado por Oliveira et al. (2003).
TABELA 1. Porcentagem de sementes de ipê-amarelo (Tabebuia serratifolia Vahl Nich.) e ipê-roxo (T. impetiginosa (Martius ExA. P. de Candolle) Standley) classificadas em categorias de acordo com a análise radiográfica. UFLA, Lavras, MG, 2004.

\begin{tabular}{cccc}
\hline ESPÉCIE & LOTES & CATEGORIAS & PORCENTAGENS \\
\hline Ipê-amarelo & \multirow{2}{*}{1998} & Sem Defeitos & 80 \\
& & Com Defeitos & 12 \\
& & Vazias & 8 \\
\cline { 2 - 4 } & \multirow{2}{*}{2002} & Sem Defeitos & 73 \\
& & Com Defeitos & 15 \\
Ipê-roxo & \multirow{2}{*}{2000} & Sem Defeitos & 12 \\
& & Com Defeitos & 86 \\
& & Vazias & 8 \\
\cline { 3 - 4 } & \multirow{2}{*}{2002} & Sem Defeitos & 6 \\
& & Com Defeitos & 75 \\
& & Vazias & 17 \\
& & & 8 \\
\hline
\end{tabular}

TABELA 2. Resultados do teste de germinação, em porcentagem, para cada categoria e lotes de sementes ipê-amarelo (Tabebuia serratifolia Vahl Nich.) e ipê-roxo ( $T$. impetiginosa (Martius Ex A. P. de Candolle) Standley). PN - plântulas normais, PA - plântulas anormais, SM - sementes mortas. UFLA, Lavras, MG, 2004.

\begin{tabular}{lclrrr}
\hline ESPÉCIE & LOTES & CATEGORIAS & PN & PA & SM \\
\hline Ipê-amarelo & 1998 & Sem Defeitos & $18 \mathrm{a}$ & 4 & 78 \\
& & Com Defeitos & $14 \mathrm{a}$ & 0 & 86 \\
\cline { 2 - 6 } & 2002 & Sem Defeitos & $85 \mathrm{a}$ & 4 & 11 \\
& & Com Defeitos & $63 \mathrm{~b}$ & 4 & 33 \\
\hline Ipê-roxo & 2000 & Sem Defeitos & $39 \mathrm{a}$ & 0 & 61 \\
& & Com Defeitos & $1 \mathrm{~b}$ & 4 & 95 \\
\cline { 2 - 6 } & \multirow{2}{*}{2002} & Sem Defeitos & $83 \mathrm{a}$ & 4 & 13 \\
& & Com Defeitos & $20 \mathrm{~b}$ & 10 & 70 \\
\hline
\end{tabular}

Por outro lado, a maioria das sementes Com Defeitos, em ambas as espécies, exceto lote 2002 de ipê-amarelo, originou sementes mortas ao final do teste de germinação, indicando que os defeitos identificados nas radiografias afetam a qualidade de lotes de sementes (Tabela 2).

Em todos os lotes das duas espécies, a maior porcentagem das sementes Com Defeitos, era composta por Pequenos Danos (Tabela 3). A intensidade de danos visualizados em sementes de espécies florestais depende do histórico do lote. Fatores como equilíbrio higroscópico, grau de umidade das sementes e temperatura, afetam a qualidade das sementes durante o processo de colheita e beneficiamento. Nesse sentido, observações, como intensidade de predação das sementes e condições climáticas durante a maturação, 
são também fundamentais para o conhecimento da qualidade do lote.

Em relação às subcategorias, verificou-se que os defeitos resultaram, em sua maioria, em sementes mortas (Tabela 4), exceto para o lote 2002 de ipê-amarelo, no qual essa observação foi feita somente na subcategoria sementes Deformadas. Dessa forma, o teste de raios X torna-se uma valiosa ferramenta em estudos relacionados às sementes de ipê-amarelo e ipê-roxo; auxiliando na seleção de lotes de diferentes qualidades e possibilitando a melhoria desses lotes pelo descarte de sementes vazias e defeituosas.

TABELA3. Porcentagem de sementes de ipê-amarelo (Tabebuia serratifolia Vahl Nich.) e ipê-roxo (T. impetiginosa (Martius ExA. P. de Candolle) Standley) classificadas em subcategorias de acordo com a análise radiográfica. UFLA, Lavras, MG, 2004.

\begin{tabular}{cccc}
\hline ESPÉCIE & LOTES & SUBCATEGORIAS & PORCENTAGENS \\
\hline Ipê-amarelo & 1998 & Pequenos Danos & 75 \\
& & Danos Severos & 11 \\
& & Deformadas & 14 \\
\cline { 2 - 4 } & 2002 & Pequenos Danos & 81 \\
& & Danos Severos & 8 \\
& & Deformadas & 11 \\
\hline Ipê-roxo & 2000 & Pequenos Danos & 48 \\
& & Danos Severos & 26 \\
& & Deformadas & 26 \\
\cline { 2 - 4 } & \multirow{2}{*}{2002} & Pequenos Danos & 57 \\
& & Danos Severos & 10 \\
& & Deformadas & 33 \\
\hline
\end{tabular}

TABELA4. Resultados do teste de germinação, em porcentagem, para cada tipo de dano visualizado pelas radiografias, em lotes de sementes de ipê-amarelo (Tabebuia serratifolia Vahl Nich.) e ipê-roxo (T. impetiginosa (Martius Ex A. P. de Candolle) Standley). PN - plântulas normais, PA-plântulas anormais, SM - sementes mortas. UFLA, Lavras, MG, 2004.

\begin{tabular}{lccrrr}
\hline ESPÉCIE & LOTES & CATEGORIAS & PN & PA & SM \\
\hline Ipê-amarelo & 1998 & Pequenos Danos & $19 \mathrm{a}$ & 0 & 81 \\
& & Danos Severos & $0 \mathrm{~b}$ & 0 & 100 \\
& & Deformadas & $0 \mathrm{~b}$ & 0 & 100 \\
\cline { 2 - 6 } & 2002 & Pequenos Danos & $67 \mathrm{~b}$ & 5 & 28 \\
& & Danos Severos & $80 \mathrm{a}$ & 0 & 20 \\
& & Deformadas & $0 \mathrm{c}$ & 0 & 100 \\
\hline Ipê-roxo & 2000 & Pequenos Danos & $9 \mathrm{a}$ & 0 & 91 \\
& & Danos Severos & $0 \mathrm{~b}$ & 0 & 100 \\
& & Deformadas & $0 \mathrm{~b}$ & 0 & 100 \\
\cline { 2 - 6 } & 2002 & Pequenos Danos & $22 \mathrm{~b}$ & 7 & 71 \\
& & Danos Severos & $33 \mathrm{a}$ & 0 & 67 \\
& & Deformadas & $10 \mathrm{c}$ & 30 & 50 \\
\hline
\end{tabular}

Resultados semelhantes foram obtidos em sementes de Pinus densiflora, P. koraiensis, P. rígida e Larix leptolepis. Além das categorias encontradas, como sementes Deformadas e Vazias, o nível de desenvolvimento das sementes pôde ser diagnosticado sem dificuldade e com precisão pelo método de raios $X$.

\section{CONCLUSÕES}

O teste de raios $\mathrm{X}$ é eficiente na avaliação dos defeitos em sementes de ipê-amarelo e ipê-roxo.

Defeitos internos detectados nas radiografias afetam a germinação dessas sementes, reduzindo a qualidade do lote.

\section{REFERÊNCIAS}

BATTISTI, A.; CANTINI, R.; FECI, E.; FRIGIMELICA, G.; GUIDO, M.; ROQUES, A. Detection and evaluation of seed damage of cypress, Cupressus sempervirens L. , in Italy. Seed Science and Technology, Zurich, v. 28, n. 3, p. 729-738, 2000.

BINO, R. J.; AARTSE, J. W.; VAN DER BURG, W. J. Nondestructive X-ray of Arabidopsis embryo mutants. Seed Science Research, Wallingford, v. 3, n. 2, p. 167-170, 1993.

BRASIL. Ministério da Agricultura e Reforma Agrária. Regras para análise de sementes. Brasília: SNDA/DNDV/CLAV, 1992. 365 p.

BURG, W. J. van der; AARTSE, J. W.; VAN ZWOL, R. A.; JALINK, H.; BINO, R. J. Predicting tomato seedling morphology by X-ray analysis of seeds. Journal American Society for Horticultural Science, Alexandria, v. 119, n. 2, p. 258-263, 1994.

CRAVIOTTO, R. M.; YOLDJIAN, A. M.; SALINAS, A. R.; ARANGO, M. R.; BISARO, V.; MATURO, H. Description of pure seed fraction of oat through usual evaluations and radiographic images. Pesquisa Agropecuária Brasileira, Brasília, v. 37, n. 8, p. 1183-1188, 2002.

INTERNATIONAL RULES FOR SEED TESTING. Seed Science and Technology. Zürich: ISTA, 1999. 333 p. (Supplement. )

MACHADO, C. F. Metodologia para a condução do teste de germinação em sementes de ipê-amarelo (Tabebuia serratifolia (Vahl) Nicholson - Bignoniaceae). Lavras: UFLA, 1999. 19 p. (Monografia).

MACHADO, C. F.; CICERO, S. M. Aroeira-branca (Lithraea molleoides (Vell.) Engl. - Anacardiaceae) seed quality evaluation by the X-ray test. Scientia Agricola, Piracicaba, v. 60, n. 2, p. 393 397. 2003.

MATTOS P. P.; MEDEIROS, A. C. S. Uso de raios-x na avaliação de sementes de pata-de-vaca (Bauhinia forticata) e erva-mate (Ilex paraguariensis). Colombo: EMBRAPA, 2000. 3 p. (Pesquisa em Andamento, n. 88).

OLIVEIRA, L. M.; CARVALHO, M. L. M.; DAVIDE, A. C. Utilização do teste de raios-X na avaliação da qualidade de sementes de 
canafístula (Peltophorum dubium (Sprengel) Taubert). Revista Brasileira de Sementes, Brasília, v. 25, n. 1, p. 116-120, 2003.

SIMAK, M. Testing of forest tree and shrub seeds by $\mathrm{X}$ radiography. In: GORDON, A. G.; GOSLING, P.; WANG, B. S. P. (Ed.) Tree and shrub seed handbook. Zurich: ISTA, 1991.
ZONTA, E. F.; MACHADO, A. A.; SILVEIRA JUNIOR, P. Sistema de análise estatística (SANEST) para microcomputador (versão 1. 0). In: SIMPÓSIO DE ESTATÍSTICA APLICADA À EXPERIMENTAÇÃO AGRONÔMICA, 1985, Piracicaba. p. 74-90.

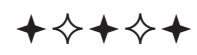

